\title{
Social-support needs among adolescents living with HIV in transition from pediatric to adult care in Cambodia: findings from a cross-sectional study
}

Graham Toth', Gitau Mburu², Sovannary Tuot ${ }^{3}$, Vohith $\mathrm{Khol}^{4}$, Chanrith Ngin ${ }^{3}$, Pheak Chhoun ${ }^{3}$ and Siyan $\mathrm{Yi}^{3,5^{*}}$ (D)

\begin{abstract}
Background: Understanding the circumstances of adolescents living with HIV is critical in designing adolescentfriendly services that will facilitate successful transition from pediatric to adult care. This study describes access, utilization and ongoing social support needs among adolescents living with HIV aged 15-17 in transition from pediatric to adult HIV care in Cambodia.

Methods: A cross-sectional study was conducted among 328 adolescents, randomly selected from 11 antiretroviral therapy (ART) clinics across the country. Descriptive analyses were conducted to summarize their characteristics, access to social support and ongoing support needs among male and female adolescents.

Results: Mean age of the study participants was $15.8(\mathrm{SD}=0.8)$ years. Just over half (55.2\%) were male. Most had at least one deceased parent (mother 50.9\%; father 60.5\%), and majority were living with biological parents (40.8\%) or relatives (49.3\%). A third came from families with an ID poor card, and 21.0\% were working for pay. Almost half (46.6\%) reported that their family had received social support for their health care, including food support (76.5\%), school allowance (62.1\%), transport allowance to ART clinics (53.6\%), psychosocial counseling (35.3\%), vocational training (22.9\%) or home visits (11.1\%). Several ongoing social support needs were identified, including ongoing inability to cover health expenses unless they are supported by health insurance or health equity fund (55.0\%). In addition, adolescents reported having been asked to come back earlier than their scheduled appointment (13.7\%), having had to purchase their own drugs (2.7\%), experiencing HIV stigma (32.0\%), having been denied housing or food due to HIV (8.2\%) or failing to attend school within the past month partly because of HIV (16.8\%). Two-thirds did not have access to peer support groups.
\end{abstract}

Conclusions: Social protection mechanisms are reaching some adolescents in need, while other remain without social support due to discontinuities in health and social care. Multi-sectoral interventions, supporting school attendance, adolescent-friendly clinic scheduling, reductions in child employment, mitigation of HIV-related stigma and strengthening of peer-to-peer support are required to improve coverage of social protection interventions for adolescents in transition.

Keywords: HIV, Adolescents, Transition, Social support, Social protection, Cambodia

\footnotetext{
*Correspondence: siyan@doctor.com

${ }^{3}$ KHANA Center for Population Health Research, No. 33, Street 71, Phnom

Penh, Cambodia

Full list of author information is available at the end of the article
} 


\section{Background}

Adolescents, defined as people aged 10-19 years, undergo rapid psychological, sexual and physical maturity [1]. Adolescents experience marked changes in sexuality [2], mental capacity [3], self-efficacy and independence [4]. At the same time, adolescents are one of the most affected populations by HIV. Globally, over two million adolescents are living with HIV [5]. Given the dynamic changes during adolescence, studies exploring outcomes of HIV care tend to distinguish adolescents living with HIV from both pediatric and adult populations.

Evidence from these studies shows that adolescents' access and outcomes of care are generally sub-optimal. Compared to adults, adolescents have poorer rates of HIV testing, disclosure [6], treatment adherence [7], long-term immunologic recovery [8] and viral suppression $[9,10]$. In addition, adolescents often face denial of care by their legal guardians and parents [11], are inexperienced in negotiation for safer sex during sexual debut $[12,13]$ and may be unable to obtain services due to restrictive parental consent laws [14]. Exploration of causes and potential solutions to these poor outcomes have generally focused on biomedical and health system solution [15].

However, the issues of social support for adolescents living with HIV are increasingly occupying a center stage. Due to the increasing survival of children living with HIV into adolescence [16], some of whom were orphans or had lost their primary caregivers $[17,18]$, there is rising recognition that they require social support to adjust socially and psychologically to living with HIV $[19,20]$.

The influence of social support on adolescent's selfefficacy [4], uptake of new services, acceptance of their diagnosis and treatment adherence [21, 22] have been documented in recent studies. Additionally, peer support groups have been shown to have a positive impact on disclosure, mental health [23] and uptake of HIV services [24] among adolescents. Furthermore, structural social protection interventions - such as cash transfers, food security, school fees and feeding programs-have been shown to have a positive impact on adolescents' adherence to antiretroviral therapy (ART) and general wellbeing [25].

These findings suggest that social support and protection are essential in achieving positive health outcomes among adolescents living with HIV. However, adolescents are not a homogenous group, but instead, they have evolving social needs in tandem with their physical and psychological maturity [26]. Studies suggest that older adolescents are particularly at risk of poorer HIV outcomes during their transition from pediatric to adult HIV care [27]. During this period, adolescents living with HIV are at high risk of poor adherence to ART [28], disengagement from HIV care [29], immunological deterioration [30] and death [5, 31].

However, there is a paucity of research exploring social support during adolescents' transition from pediatric to adult HIV care. Most of the existing studies tend to focus on clinical and biomedical (e.g., virological, retention and mortality) outcomes during and after transition to adult care $[28,29,32,33]$, with little focus on the social support interventions or needs specific to this group. As a result, social support for adolescents living with HIV remain undocumented and unaddressed [30]. This paper describes utilization and ongoing social support needs among adolescents living with HIV aged 15-17 in transition from pediatric to adult care in Cambodia and discusses the implications of the findings on a successful transition from pediatric to adult HIV care.

\section{Methods}

\section{Study design and settings}

This cross-sectional study was conducted in August 2016 among 328 adolescents living with HIV, randomly selected from 11 ART clinics throughout Cambodia. The details of the study have been reported elsewhere [34]. Briefly, we applied a two-stage sampling design to identify 598 eligible participants from the 18 major ART clinics countrywide. Twenty-one clinics with less than 10 adolescents living with HIV each were excluded to minimize cost. The sample size was set at 320 , calculated to estimate a high level of preparedness of $60 \%$ with a confidence interval (CI) of $95 \%$ and design effect of 1.4 using a probability proportional to size method [35]. Eligible subjects were selected using a random number table.

\section{Participant recruitment}

Selected adolescents were screened via telephone and informed of research objectives as well as place, date and time of the interview. Adolescents would be asked to participate if they were between 15 and 17 years of age, receiving treatment and care services, able to communicate in Khmer, allowed by a parent or guardian to participate, their parent or caregiver was willing to provide a written consent, able to present themselves on the day of the interview and physically and mentally stable to provide verbal assent to participate. Upon confirming eligibility, a written consent from their parent or guardian was obtained. Recruitment continued until the required sample size for each clinic was achieved.

\section{Questionnaire development}

Questionnaire development was guided by existing literature [36, 37]. Information on socio-demographic characteristics, perceived health status, school attendance, disclosure, stigma experience, psychosocial support and 
medication supply and ART adherence were collected through self-reported interviews. Clinical and immunological data, including HIV status, ART history and laboratory values for $\mathrm{CD} 4$ and viral loads were obtained from medical records.

\section{Data collection and training}

Data were collected by two teams of interviewers and moderators who were trained on study protocol, questionnaire administration, confidentiality and issues related to research with human participants [38]. Pretesting was conducted among 20 adolescents living with HIV and 10 parents and guardians, and questionnaire adjustments were made.

\section{Data analyses}

Data were classified and scaled continuously or categorically as appropriate and recorded into a computerized database using EpiData version 3 (Odense, Denmark). Double data entry was implemented to minimize errors. Descriptive analyses were performed to determine frequency distribution for categorical variables and mean with standard deviation (SD) for continuous variables. Chi square, Fisher's exact or t-test tests for significance were used to compare characteristics of male and female adolescents. p-values of less than 0.05 were considered statistically significant.

\section{Ethical considerations}

The study was approved by the National Ethics Committee for Health Research, Ministry of Health in Cambodia (Ref: 297NECHR). Assent from participants and a written informed consent from a parent or guardian was obtained. Data were collected in private locations, and confidentiality protected by removing all personal identifiers from questionnaires. Participants were provided with a token of $\$ 2.5-\$ 5$ for transportation.

\section{Results}

\section{Characteristics and of the study sample}

Of the 328 adolescents, $51.3 \%$ had completed secondary (7-9 years) school, less than half $(42.7 \%)$ were living with one or both parents, and $55.2 \%$ were male. Parents $(40.8 \%)$ or relatives $(33.6 \%)$ were the most frequently reported caregivers. More than half of respondents had at least one deceased parent (mother 50.9\%; father 60.5\%). Maternal and paternal educational levels were both $20 \%$ for high school (10-12 years) or university education (Table 1).

\section{Access and adherence to ART}

On average, ART refills were dispensed every two months. Forty-five participants (13.7\%) reported having to return earlier than their scheduled appointment due to inadequate supply of medicines $(22.2 \%)$ or the need for an additional check-up (46.7\%). A small number (2.7\%) had been asked to purchase their own drugs. Notably, sharing of ART was not reported (Table 2).

\section{Stigma and discrimination}

Thirty-two percent reported negative attitudes or being mistreated (10.7\%) because of their HIV status; $8.2 \%$ had been denied housing or food (Table 3).

\section{School attendance, employment and social support}

Within the past month, $22.9 \%$ experienced disruptions with attendance at school, and $16.8 \%$ reported that they were no longer enrolled. Being too ill (34.1\%), lack of fees (14\%) or poor academic performance $(18.6 \%)$ were the most frequently reported reasons for being absent. Only a fraction $(0.6 \%)$ of the 69 adolescents currently working for pay sought employment outside of their hometown. Almost half (46.6\%) reported that their family had received social support for their health care, including food support $(76.5 \%)$, school allowance (62.1\%), transport allowance to ART clinic (53.6\%), emotional counseling (35.3\%), vocational training (22.9\%) and home visit $(11.1 \%)$. Thirty percent belonged to a peer support group (Table 4).

\section{Assessment of preparedness for transition}

The majority (72.0\%) of respondents were able to recognize when they were getting sick, and $80.5 \%$ knew when they needed to call a health care provider. However, less than half $(46.0 \%)$ reported being the one responsible for scheduling follow-up visits, and $13.4 \%$ indicated that they felt comfortable asking health questions during appointments. An approximately equal number of males and females reported some degree of difficulty with ART adherence. The average visual adherence scale score between the two groups was $95.4 \%(\mathrm{SD}=9.6 \%$ ) (Table 5).

Significantly, females were less likely to retain copies of their health records and doctor contacts $(32.7 \%$ vs. $57.4 \%, p<0.001$ ), less likely to report having a method for organizing HIV-related appointments $(47.9 \%$ vs. $72.8 \%$, $p<0.001)$ and more likely to report that they would discontinue ART when feeling ill ( $7.1 \%$ vs. $15.1 \%, p=0.02)$ (Table 5).

\section{Experiences of preparation for transition}

About one-third (29.6\%) had received counseling on the transition to adult services. However, only $2.7 \%$ of them had completed a transfer form, and $19.7 \%$ had visited an adult ART clinic to prepare for the transition. About one-forth $(24.7 \%)$ reported that a case manager had been identified to support them during the transition. The 
Table 1 Socio-demographic characteristics of male and female adolescents living with HIV

\begin{tabular}{|c|c|c|c|c|}
\hline Socio-demographic characteristics & Total $(n=328), n(\%)$ & Male $(n=169), n(\%)$ & Female $(n=159), n(\%)$ & $P$-value* \\
\hline Mean age (in years) & $15.9 \pm 0.8$ & $15.8 \pm 0.8$ & $16.0 \pm 0.8$ & 0.06 \\
\hline Type of ART regimen & & & & 0.91 \\
\hline First line & $183(82.4)$ & $140(82.8)$ & $131(82.4)$ & \\
\hline Second line & $36(16.2)$ & $29(17.2)$ & $27(17.6)$ & \\
\hline Duration on ART (in months) & $101 \pm 40$ & $99.8(40.7)$ & $94.0(39.6)$ & 0.20 \\
\hline Initial CD4 count (cells/mm³) & $632 \pm 110$ & $777 \pm 1460$ & $632 \pm 460$ & 0.35 \\
\hline Latest CD4 count (cells $/ \mathrm{mm}^{3}$ ) & $672 \pm 284$ & $683 \pm 314$ & $660 \pm 250$ & 0.44 \\
\hline First viral load count (copies) & $34,375 \pm 13,958$ & $37,868 \pm 13,205$ & $30,662 \pm 14,748$ & 0.64 \\
\hline Latest viral load count (copies) & $9268 \pm 6407$ & $4103 \pm 1573$ & $14,759 \pm 9041$ & 0.13 \\
\hline Visual adherence scale (\%) & $95.4 \pm 9.6$ & $95.3 \pm 9.6$ & $95.4 \pm 9.7$ & 0.91 \\
\hline Travel time to ART clinic (min) & $48.2 \pm 43.4$ & $46.1 \pm 41.2$ & $55.5 \pm 45.5$ & 0.36 \\
\hline Cost to travel to clinic (USD) & $3.4 \pm 3.9$ & $3.5 \pm 3.9$ & $3.3 \pm 4.0$ & 0.61 \\
\hline Level of formal education ${ }^{\mathrm{a}}$ & & & & 0.76 \\
\hline Primary school or lower & $92(28.0)$ & $50(20.7)$ & $42(26.4)$ & \\
\hline Secondary school & $168(51.3)$ & $86(50.9)$ & $82(51.6)$ & \\
\hline High school or higher & $68(20.7)$ & $33(19.5)$ & $35(22.0)$ & \\
\hline Ability to cover health expenses & & & & 0.11 \\
\hline No & $181(55.2)$ & $86(50.9)$ & $95(59.7)$ & \\
\hline Yes & $147(44.8)$ & $83(49.3)$ & $64(40.3)$ & \\
\hline Family has an ID poor card & & & & 0.04 \\
\hline No & $190(57.9)$ & $88(52.1)$ & $102(64.2)$ & \\
\hline Yes & $112(34.2)$ & $63(37.3)$ & $49(30.8)$ & \\
\hline Don't know & $26(7.9)$ & $18(10.7)$ & $8(5.0)$ & \\
\hline Access to the health equity fund & & & & $<0.001$ \\
\hline No & $185(56.4)$ & $109(64.5)$ & $76(47.8)$ & \\
\hline Yes & $126(38.4)$ & $45(35.7)$ & $81(50.9)$ & \\
\hline Don't know & $17(5.2)$ & $15(8.9)$ & $2(1.3)$ & \\
\hline Covered by health insurance & & & & 0.02 \\
\hline No & $289(88.1)$ & $148(87.6)$ & $141(88.7)$ & \\
\hline Yes & $148(87.6)$ & $0(0.0)$ & $6(3.8)$ & \\
\hline Don't know & $33(10.1)$ & $21(12.4)$ & $12(7.5)$ & \\
\hline Currently living with & & & & 0.33 \\
\hline Parents & $140(42.7)$ & $73(43.2)$ & $67(42.1)$ & \\
\hline Grandparents & $49(14.9)$ & $29(12.7)$ & $20(12.6)$ & \\
\hline Relatives & $106(32.3)$ & $54(32.0)$ & $52(32.7)$ & \\
\hline In an orphanage & $27(8.2)$ & $12(7.1)$ & $15(9.4)$ & \\
\hline Other & $6(1.8)$ & $1(0.6)$ & $5(3.1)$ & \\
\hline Type of accommodation & & & & 0.94 \\
\hline Flat/apartment & $19(8.9)$ & $10(8.7)$ & $9(8.4)$ & \\
\hline Hut & $12(5.4)$ & $7(6.1)$ & $5(4.7)$ & \\
\hline Mid-size country house & $173(73.7)$ & $88(78.7)$ & $85(79.4)$ & \\
\hline Mansion/large country house & $12(5.4)$ & $6(5.2)$ & $6(5.6)$ & \\
\hline Other & $6(2.7)$ & $4(3.5)$ & $2(1.9)$ & \\
\hline \multicolumn{5}{|l|}{ Family possessions } \\
\hline Running water & $123(55.4)$ & $61(53.0)$ & $62(57.9)$ & 0.46 \\
\hline Electricity & $195(87.8)$ & $102(88.7)$ & $93(86.9)$ & 0.69 \\
\hline Television & $167(75.2)$ & $88(76.5)$ & $79(73.8)$ & 0.64 \\
\hline Radio & $77(34.7)$ & $45(39.1)$ & $32(29.9)$ & 0.15 \\
\hline Fridge & $30(13.5)$ & $13(11.3)$ & $17(15.9)$ & 0.32 \\
\hline Private latrine & $182(82.0)$ & $96(83.5)$ & $86(80.4)$ & 0.55 \\
\hline
\end{tabular}


Table 1 continued

\begin{tabular}{|c|c|c|c|c|}
\hline Socio-demographic characteristics & Total $(n=328), n(\%)$ & Male $(n=169), n(\%)$ & Female $(n=159), n(\%)$ & $P$-value* \\
\hline Mother is still alive & & & & 0.18 \\
\hline No & $167(50.9)$ & $80(47.3)$ & $87(54.7)$ & \\
\hline Yes & $161(49.1)$ & $89(52.7)$ & $72(45.3)$ & \\
\hline Mother's education level ${ }^{a}$ & & & & 0.12 \\
\hline No education & $20(12.7)$ & $7(8.1)$ & $13(18.1)$ & \\
\hline Primary school & $53(33.5)$ & $27(31.4)$ & $26(36.1)$ & \\
\hline Secondary school & $24(15.2)$ & $14(16.3)$ & $10(13.9)$ & \\
\hline High school or higher & $24(15.2)$ & $12(14.0)$ & $12(16.7)$ & \\
\hline Don't know & $37(23.4)$ & $26(30.2)$ & $11(15.3)$ & \\
\hline Father is still alive & & & & 0.82 \\
\hline No & $198(60.4)$ & $101(59.8)$ & $97(61.0)$ & \\
\hline Yes & $130(39.6)$ & $68(40.2)$ & $62(39.0)$ & \\
\hline Father's education level ${ }^{\mathrm{a}}$ & & & & 0.04 \\
\hline No education & $9(5.6)$ & $4(6.2)$ & $3(4.3)$ & \\
\hline Primary school & $33(26.2)$ & $12(18.8)$ & $21(33.9)$ & \\
\hline Secondary school & $18(14.3)$ & $8(12.5)$ & $10(16.1)$ & \\
\hline High school or higher & $28(24.3)$ & $9(14.1)$ & $14(22.6)$ & \\
\hline Don't know & $45(35.7)$ & $31(48.4)$ & $14(22.6)$ & \\
\hline Main daily caregiver & & & & 0.57 \\
\hline Parent & $187(57.0)$ & $102(60.4)$ & $85(53.5)$ & \\
\hline Grand parent & $5(1.5)$ & $2(1.2)$ & $3(1.9)$ & \\
\hline Sibling & $24(7.3)$ & $9(5.3)$ & $15(9.4)$ & \\
\hline Relatives & $100(30.5)$ & $50(29.6)$ & $50(31.4)$ & \\
\hline Orphanage/NGO staff & $12(3.7)$ & $6(3.6)$ & $6(3.8)$ & \\
\hline Main caregiver's education level ${ }^{a}$ & & & & $<0.001$ \\
\hline Primary school or lower & $14(7.2)$ & $2(2.1)$ & $12(12.1)$ & \\
\hline Secondary school & $40(20.5)$ & $8(8.3)$ & $32(32.3)$ & \\
\hline High school & $11(5.6)$ & $6(6.2)$ & $5(5.1)$ & \\
\hline University or higher & $29(14.9)$ & $16(16.7)$ & $13(13.1)$ & \\
\hline Don't know & $101(51.8)$ & $64(66.7)$ & $37(37.4)$ & \\
\hline
\end{tabular}

ART antiretroviral therapy, HIV human immunodeficiency virus, NGO non-governmental organization, USD United States Dollar

* Chi square or Fisher's exact test was used as appropriate for categorical variables, Student's t-test was used for continuous variables

a Primary $=$ less than or equal to 6 years, secondary $=7-9$ years, high school $=10-12$ years

majority of them felt supported during the preparation process for transition with $14.5 \%$ feeling very supported, and $59.5 \%$ felt somewhat supported. Sixty-six percent preferred to receive pediatric HIV-related care. Issues related to health, sexuality or daily life were most frequently discussed with family (47.9\%), health providers (20.4\%) and friends (13.4\%). However, health care providers $(79 \%)$ were reported as the most trusted source of information for HIV care and treatment (Table 6).

Males were significantly more likely to discuss health problems with medical providers $(26.6 \%$ vs. $13.8 \%$, $p=0.01$ ), and they were also more likely to trust friends or family members the most for their treatment (14.8\% vs. $6.9 \%, p=0.02)$. Preparation strategies among males were more likely to include a visit to an adult clinic
(34.9\% vs. $21.4 \%, p=0.007)$ despite having a lower likelihood of being assigned a case manager (33.7\% vs. $49.7 \%$, $p=0.003$ ) or of including counselors or peer-educators in their transition plans $(1.8 \%$ vs. $6.9 \%, p=0.02)$. Overall, male participants reported feeling more prepared for the transition to adult services $(96.5 \%$ vs. $80.5 \%, p<0.001)$, despite being more likely to report feeling inadequately supported (77.6\% vs. 92.4\%, $p=0.006$ ) (Table 6).

\section{Discussion}

Our cross-sectional study describes the dynamic social circumstances unique to Cambodian adolescents living with HIV as they transition to adult clinics. We found that social protection mechanism are reaching some adolescents living with HIV in need. Almost half reported 
Table 2 Access and adherence to ART among male and female adolescents living with HIV

\begin{tabular}{|c|c|c|c|c|}
\hline Access and adherence to ART & $\begin{array}{l}\text { Total }(n=328) \\
n(\%)\end{array}$ & $\begin{array}{l}\text { Male }(n=169) \\
n(\%)\end{array}$ & $\begin{array}{l}\text { Female }(n=159) \\
n(\%)\end{array}$ & $p$-value* \\
\hline Mean number of days the drug supply is usually given & $58.4 \pm 53.9$ & $61.4 \pm 73.7$ & $55.1 \pm 14.9$ & 0.3 \\
\hline Ever shared your drugs to other persons & & & & - \\
\hline No & $328(100)$ & $169(100)$ & $159(100)$ & \\
\hline Yes & $0(0.0)$ & $0(0.0)$ & $0(0.0)$ & \\
\hline Having been asked to come back earlier than appointment & & & & 0.56 \\
\hline No & $283(86.3)$ & $144(85.2)$ & $139(87.4)$ & \\
\hline Yes & $45(13.7)$ & $25(14.8)$ & $20(12.6)$ & \\
\hline Reasons for coming back earlier than appointment & & & & 0.35 \\
\hline Lack of medicines & $10(22.2)$ & $5(20.0)$ & $5(25.0)$ & \\
\hline Additional check up & $21(46.7)$ & $10(40.0)$ & $11(55.0)$ & \\
\hline Other & $14(31.1)$ & $10(40.0)$ & $4(20.0)$ & \\
\hline Having been asked to buy any other medicines & & & & 0.81 \\
\hline No & $319(97.3)$ & $164(97.0)$ & $155(97.5)$ & \\
\hline Yes & $9(2.7)$ & $5(3.0)$ & $4(2.5)$ & \\
\hline
\end{tabular}

Table 3 Experiences of stigma and discrimination among male and female adolescents living with HIV

\begin{tabular}{|c|c|c|c|c|}
\hline Experiences of stigma and discrimination & $\begin{array}{l}\text { Total }(n=328) \\
n(\%)\end{array}$ & $\begin{array}{l}\text { Male }(n=169) \\
n(\%)\end{array}$ & $\begin{array}{l}\text { Female }(n=159) \\
n(\%)\end{array}$ & $p$-value* \\
\hline \multicolumn{4}{|c|}{ Someone has mistreated you because of your HIV-infected status } & 0.28 \\
\hline No & $293(89.3)$ & $154(91.1)$ & $139(87.4)$ & \\
\hline Yes & $35(10.7)$ & $15(8.9)$ & $20(12.6)$ & \\
\hline \multicolumn{4}{|c|}{ Having experienced negative attitudes because of your HIV-infected status } & 0.09 \\
\hline No & $223(68.0)$ & $122(72.2)$ & $101(63.5)$ & \\
\hline Yes & $105(32.0)$ & $47(27.8)$ & $58(36.5)$ & \\
\hline \multicolumn{4}{|c|}{ Having been refused to share housing/other materials because of your HIV-infected status } & 0.66 \\
\hline No & $301(91.8)$ & $154(91.1)$ & $147(92.5)$ & \\
\hline Yes & $27(8.2)$ & $15(8.9)$ & $12(7.5)$ & \\
\hline
\end{tabular}

that their family had received at least one element of social support for their health care, ranging from food support, school allowance, transport allowance to ART clinics, psychosocial counseling, vocational training, or home visits. Of these, food support and school allowance had the highest coverage.

At the same time, significant social support needs were identified, including ongoing inability ability to cover health expenses (55.0\%), stigma and discrimination and lack of access to peer support groups. Some of these needs intersected with health system factors such as lack of HIV treatment, failure to received counselling on transition, low rate of familiarization with adult clinics and allocation of a transition case manager.

The numbers of participants accessing the social supports indicate that current interventions have the capacity-building potential to reach adolescents living with
HIV from poorer communities. This is important given that socioeconomic and social health protection status are significant determinants of a successful move to adult-oriented medical care [30, 39]. Evidence from other setting suggests that both adolescents living with HIV and their health care providers consider poor socioeconomic conditions to be a significant barrier to the transition process [30].

We uncovered remarkable differences in how male and female adolescents living with HIV communicate their health needs and manage their care and treatment. Our data shows that female adolescents have difficulty managing their own care, including discussing their medical concerns with their health care providers, which may explain the more frequent reports of ART non-adherence among female adolescents when feeling sick. Future studies may elucidate how gender and gender responsibilities 
Table 4 School attendance and employment history among male and female adolescents living with HIV

\begin{tabular}{|c|c|c|c|c|}
\hline School attendance and employment history & Total $(n=328), n(\%)$ & Male $(n=169), n(\%)$ & Female $(n=159), n(\%)$ & $p$-value* \\
\hline School attendance in the past month & & & & 0.79 \\
\hline Never & $55(16.8)$ & $29(17.2)$ & $26(16.4)$ & \\
\hline With disruptions & $75(22.9)$ & $36(21.3)$ & $39(24.5)$ & \\
\hline Full time & $198(60.4)$ & $104(61.5)$ & $94(59.1)$ & \\
\hline Age when stopped going to school & $14.7 \pm 1.5$ & $14.7 \pm 1.2$ & $14.6 \pm 1.8$ & 0.48 \\
\hline Reasons for not attending school & & & & 0.25 \\
\hline No money to go to school & $18(14.0)$ & $6(9.4)$ & $12(18.5)$ & \\
\hline Too sick to go to school & $44(34.1)$ & $20(31.2)$ & $24(36.9)$ & \\
\hline Not successful at school & $24(18.6)$ & $15(23.4)$ & $9(13.8)$ & \\
\hline Other & $43(33.3)$ & $23(35.9)$ & $20(30.9)$ & \\
\hline Currently working for pay & & & & 0.34 \\
\hline No & $259(79.0)$ & $137(81.1)$ & $122(76.7)$ & \\
\hline Yes & $69(21.0)$ & $32(18.9)$ & $37(23.3)$ & \\
\hline Mean age when started working & $14.8 \pm 1.9$ & $15.0 \pm 1.2$ & $14.7 \pm 2.3$ & 0.54 \\
\hline Ever travelled outside of hometown for work & & & & 0.23 \\
\hline No & $326(94.4)$ & $169(100)$ & $157(98.7)$ & \\
\hline Yes & $2(0.6)$ & $0(0.0)$ & $2(1.3)$ & \\
\hline Family received social support for your health & & & & 0.85 \\
\hline No & $175(53.4)$ & $91(53.8)$ & $84(52.8)$ & \\
\hline Yes & $153(46.6)$ & $78(46.2)$ & $75(47.2)$ & \\
\hline \multicolumn{5}{|l|}{ Types of support received by family } \\
\hline Transportation allowance & $82(53.6)$ & $43(55.1)$ & $39(52.0)$ & 0.7 \\
\hline Food support & $117(76.5)$ & $57(73.1)$ & $60(80.0)$ & 31 \\
\hline School allowance & $95(62.1)$ & $46(59.0)$ & $49(65.3)$ & 0.42 \\
\hline Emotional counseling & $54(35.3)$ & $24(30.8)$ & $30(40.0)$ & 0.23 \\
\hline Vocational training & $35(22.9)$ & $14(17.9)$ & $21(28.0)$ & 0.14 \\
\hline Home visit & $17(11.1)$ & $10(12.8)$ & $7(9.3)$ & 0.49 \\
\hline Family received financial support for your health & & & & 0.95 \\
\hline No & $214(65.2)$ & $110(65.1)$ & $104(65.4)$ & \\
\hline Yes & $114(34.8)$ & $59(34.9)$ & $55(34.6)$ & \\
\hline Belonged to a patient group & & & & 0.63 \\
\hline No & $231(70.4)$ & $121(71.6)$ & $110(69.2)$ & \\
\hline Yes & $97(27.9)$ & $48(28.4)$ & $49(30.8)$ & \\
\hline
\end{tabular}

$A R T$ antiretroviral therapy, HIV human immunodeficiency virus

* Chi square or Fisher's exact test was used as appropriate for categorical variables, Student's t-test was used for continuous variables

influence the doctor-patient relationship in this setting and could form the basis for effective gender-sensitive interventions [24].

\section{Addressing social factors}

The proportion (22\%) of adolescents working for pay is concerning and may explain the lower school attendance rate in our study population. Education exerts a positive influence on adolescents living with HIV [24] and is a considerable protective factor against poor mental outcomes, risky sexual behavior and substance abuse [40, 41]. Our findings offer additional rationale to improve school retention by confronting discrimination in schools and normalizing HIV. HIV-related stigma is a primary determinant in adolescent health and is also a decisive motivator in the transition process [42]. In addition, expansion of peer support to the two-thirds of adolescents who did not belong to such groups is needed, as participation in peer support is associated with improved medical adherence [24, 43]. Given that access to available social protection support was suboptimal, our results argue for adolescent-focused interventions at multiple layers of the sociological context [24] to ensure that every needy adolescent has access to available wrap around services to support successful adolescent transition. In addition, future analyses are needed to explore 
Table 5 Assessment of preparedness for transition from pediatric to adult care among male and female adolescents living with HIV

\begin{tabular}{|c|c|c|c|c|}
\hline Assessment of preparedness for transition & Total $(n=328), n(\%)$ & Male $(n=169), n(\%)$ & Female $(n=159), n(\%)$ & $p$-value* \\
\hline \multicolumn{4}{|l|}{ Can you recognize when you are getting sick? } & 0.28 \\
\hline No & $92(28.0)$ & $43(25.4)$ & $49(30.8)$ & \\
\hline Yes & $236(72.0)$ & $126(74.6)$ & $110(69.2)$ & \\
\hline \multicolumn{4}{|l|}{ Do you know when you need to call the doctor? } & 1.00 \\
\hline No & $64(19.5)$ & $33(19.5)$ & $31(19.5)$ & \\
\hline Yes & $264(80.5)$ & $136(80.5)$ & $128(80.5)$ & \\
\hline \multicolumn{4}{|c|}{ Are you responsible for making your own appointments? } & 0.40 \\
\hline No & $177(54.0)$ & $95(56.2)$ & $82(51.6)$ & \\
\hline Yes & $151(46.0)$ & $74(43.8)$ & $77(48.4)$ & \\
\hline \multicolumn{4}{|c|}{ Are you responsible for refilling your own medications? } & 0.79 \\
\hline No & $151(46.0)$ & $79(46.7)$ & $72(45.3)$ & \\
\hline Yes & $177(54.0)$ & $90(53.3)$ & $87(54.7)$ & \\
\hline \multicolumn{4}{|c|}{ Do you feel comfortable asking questions at your appointments? } & 0.04 \\
\hline No & $284(86.6)$ & $140(82.8)$ & $144(90.6)$ & \\
\hline Yes & $44(13.4)$ & $29(17.2)$ & $15(9.4)$ & \\
\hline \multicolumn{4}{|c|}{ Do you have a copy of your health records and doctor contacts? } & $<0.001$ \\
\hline No & $179(54.6)$ & $72(42.6)$ & $107(67.3)$ & \\
\hline Yes & $149(45.4)$ & $97(57.4)$ & $52(32.7)$ & \\
\hline \multicolumn{4}{|c|}{ Do you have a method of keeping track of your healthcare appointments? } & $<0.001$ \\
\hline No & $126(38.4)$ & $46(27.2)$ & $80(50.3)$ & \\
\hline Yes & $202(61.6)$ & $123(72.8)$ & $79(49.7)$ & \\
\hline \multicolumn{4}{|c|}{ Do you find it difficult to remember to take your medicine? } & 0.21 \\
\hline No & $250(76.2)$ & $124(73.4)$ & $126(79.2)$ & \\
\hline Yes & $78(26.8)$ & $45(26.6)$ & $33(20.8)$ & \\
\hline \multicolumn{4}{|c|}{ When you feel better, do you stop taking your medicine? } & 0.14 \\
\hline No & $326(99.4)$ & $169(100)$ & $157(98.7)$ & \\
\hline Yes & $2(0.6)$ & $0(0.0)$ & $2(1.3)$ & \\
\hline \multicolumn{4}{|c|}{ If you feel worse when you take the medicine, do you stop taking it? } & 0.02 \\
\hline No & $292(89.0)$ & $157(92.9)$ & $135(84.9)$ & \\
\hline Yes & $36(11.0)$ & $12(7.1)$ & $24(15.1)$ & \\
\hline \multicolumn{4}{|c|}{ Thinking back over the past 4 days, have you missed any of your medicine? } & 0.81 \\
\hline No & $282(86.0)$ & $147(87.0)$ & $135(84.9)$ & \\
\hline Not sure & $41(12.5)$ & $20(11.8)$ & $21(13.2)$ & \\
\hline Yes & $5(1.5)$ & $2(1.2)$ & $3(1.9)$ & \\
\hline Visual adherence scale (\%) & $95.4 \pm 9.6$ & $95.3 \pm 9.6$ & $95.4 \pm 9.7$ & 0.91 \\
\hline
\end{tabular}

HIV human immunodeficiency virus

Values are number (\%) for categorical variables and mean $( \pm S D)$ for continuous variables

* Chi square or Fisher's exact test was used for categorical outcome variables and Student's t-test was used for continuous outcome variables

the socioeconomic factors driving these students out of school and into the workforce.

\section{Addressing health system factors}

An inadequate drug supply was common which may affect ART adherence and partially contribute to the high rate of school absences. Improved medication adherence is associated with a daily routine [39], which is reliant upon a consistent supply of medication. Moreover, the transition from pediatric to adult care has the potential for being a significant psychological burden [44] on adolescents living with HIV, which requires adequate supply and adolescent-friendly services, devoid of stigma. In the current context, strengthening supply of ARV will be essential. At the same time, there is a need to strengthen the provision of counselling on transition and enhance adolescent familiarization with adult clinics as part of the transition. Furthermore, despite policies requiring 
Table 6 Experience of transition from pediatric and adult care among male and female adolescents living with HIV

\begin{tabular}{|c|c|c|c|c|}
\hline Experience of transition from pediatric and adult care & Total $(n=328), n(\%)$ & Male $(n=169), n(\%)$ & Female $(n=159), n(\%)$ & $p$-value* \\
\hline \multicolumn{4}{|l|}{ Facility you prefer to receive care and treatment } & 0.46 \\
\hline Pediatric pre ART/ART services & $217(66.2)$ & $115(68.8)$ & $102(64.2)$ & \\
\hline Adult pre ART/ART service & $111(33.8)$ & $54(32.0)$ & $57(35.8)$ & \\
\hline \multicolumn{4}{|c|}{ Preferred to discuss questions related to health, sexuality, or daily life with } & 0.01 \\
\hline Health providers & $67(20.4)$ & $45(26.6)$ & $22(13.8)$ & \\
\hline Counselors/peer educators & $19(5.8)$ & $6(3.6)$ & $13(8.2)$ & \\
\hline Friends & $44(13.4)$ & $17(10.1)$ & $27(17.0)$ & \\
\hline Family & $157(47.9)$ & $81(47.9)$ & $76(47.8)$ & \\
\hline Other & $41(12.5)$ & $20(11.8)$ & $21(13.2)$ & \\
\hline \multicolumn{4}{|l|}{ Person who you trust the most for your treatment } & 0.02 \\
\hline Health providers & $259(79.0)$ & $132(78.1)$ & $127(79.9)$ & \\
\hline Counselors/peer educators & $14(4.3)$ & $3(1.8)$ & $11(6.9)$ & \\
\hline Friends/family & $36(11.0)$ & $25(14.8)$ & $11(6.9)$ & \\
\hline Other & $19(5.8)$ & $9(5.8)$ & $10(6.3)$ & \\
\hline \multicolumn{4}{|l|}{ Sources of information about health } & $<0.001$ \\
\hline Pre ART/ART clinic & $199(60.7)$ & $118(69.8)$ & $81(50.9)$ & \\
\hline NGOs & $21(6.4)$ & $10(5.9)$ & $11(6.9)$ & \\
\hline Family & $80(24.7)$ & $25(14.8)$ & $55(34.6)$ & \\
\hline Other & $28(8.5)$ & $16(9.5)$ & $12(7.5)$ & \\
\hline \multicolumn{4}{|l|}{ Current HIV care provider } & 0.06 \\
\hline Health provider for adults & $105(32.0)$ & $46(27.2)$ & $59(37.1)$ & \\
\hline Health provider for children & $223(68.8)$ & $123(72.8)$ & $100(62.9)$ & \\
\hline \multicolumn{4}{|l|}{ Received counseling on transition to adult services } & 0.49 \\
\hline No & $190(57.9)$ & $101(59.8)$ & $89(56.0)$ & \\
\hline Yes & $138(42.1)$ & $68(40.2)$ & $70(44.0)$ & \\
\hline \multicolumn{4}{|l|}{ Person who provided the counseling } & 0.34 \\
\hline Health providers & $56(40.9)$ & $31(45.6)$ & $25(36.2)$ & \\
\hline Counselors/peer educators & $64(46.7)$ & $31(45.6)$ & $33(47.8)$ & \\
\hline Other & $17(12.4)$ & $6(8.8)$ & $11(15.9)$ & \\
\hline \multicolumn{4}{|l|}{ Ever completed a transfer form } & 0.58 \\
\hline No & $292(89.0)$ & $152(89.9)$ & $140(88.1)$ & \\
\hline Yes & $36(11.0)$ & $17(10.1)$ & $19(11.9)$ & \\
\hline \multicolumn{4}{|l|}{ Ever visited an adult clinic to prepare for transition } & 0.007 \\
\hline No & $235(71.6)$ & $110(65.1)$ & $125(78.6)$ & \\
\hline Yes & $93(28.4)$ & $59(34.9)$ & $34(21.4)$ & \\
\hline \multicolumn{4}{|c|}{ Person who took you to visit the adult clinic to prepare for transition } & 0.07 \\
\hline Health providers & $8(8.7)$ & $4(6.8)$ & $4(12.1)$ & \\
\hline Counselors/peer educators & $8(8.7)$ & $2(3.4)$ & $6(18.2)$ & \\
\hline Friends/family & $58(63.0)$ & $41(69.5)$ & $17(51.5)$ & \\
\hline Other & $18(19.6)$ & $12(20.3)$ & $6(18.2)$ & \\
\hline \multicolumn{4}{|l|}{ The visit was helpful for you to cope with the transition } & 0.83 \\
\hline No & $5(5.6)$ & $3(5.2)$ & $2(6.3)$ & \\
\hline Yes & $85(94.4)$ & $55(94.8)$ & $30(93.8)$ & \\
\hline \multicolumn{4}{|c|}{ A'Case Manager' has been identified to support you during the transition } & 0.003 \\
\hline No & $192(58.5)$ & $112(66.3)$ & $80(50.3)$ & \\
\hline Yes & $136(41.5)$ & $57(33.7)$ & $79(49.7)$ & \\
\hline \multicolumn{4}{|l|}{ Preparedness to manage your treatment going forward } & $<0.001$ \\
\hline Very prepared & $42(12.8)$ & $27(16.0)$ & $15(9.4)$ & \\
\hline Somewhat prepared & $249(75.9)$ & $136(80.5)$ & $113(71.1)$ & \\
\hline
\end{tabular}


Table 6 continued

\begin{tabular}{|c|c|c|c|c|}
\hline Experience of transition from pediatric and adult care & Total $(n=328), n(\%)$ & Male $(n=169), n(\%)$ & Female $(n=159), n(\%)$ & $p$-value* \\
\hline Somewhat unprepared & $21(6.4)$ & $4(2.4)$ & $17(10.7)$ & \\
\hline Very unprepared & $16(4.9)$ & $2(1.2)$ & $14(8.8)$ & \\
\hline \multicolumn{4}{|c|}{ Feeling supported during your transition from pediatric care to adult care } & 0.006 \\
\hline Very supported & $45(25.4)$ & $17(20.0)$ & $28(30.4)$ & \\
\hline Somewhat supported & $106(59.9)$ & $49(57.6)$ & $57(62.0)$ & \\
\hline Somewhat unsupported & $13(7.3)$ & $7(8.2)$ & $6(6.5)$ & \\
\hline Very unsupported & $13(7.3)$ & $12(14.1)$ & $1(1.1)$ & \\
\hline \multicolumn{4}{|l|}{ Satisfaction you with your transition experience in general } & 0.34 \\
\hline Very satisfied & $53(16.2)$ & $29(17.2)$ & $24(15.1)$ & \\
\hline Somewhat satisfied & $107(32.6)$ & $51(30.2)$ & $56(35.2)$ & \\
\hline Somewhat dissatisfied & $34(10.4)$ & $14(8.3)$ & $20(12.6)$ & \\
\hline Very dissatisfied & $134(40.7)$ & $75(44.4)$ & $59(37.1)$ & \\
\hline
\end{tabular}

$A R T$ antiretroviral therapy, HIV human immunodeficiency virus

Values are number (\%) for categorical variables and mean $( \pm S D)$ for continuous variables

* Chi square or Fisher's exact test was used for categorical outcome variables and Student's t-test was used for continuous outcome variables

allocation of a transition case manager, only a quarter of adolescents in this study had been allocated one. This will also need to be enhanced in order to support successful transition of adolescents to adult HIV care. Transition managers provide and link adolescents to available social support and protection.

\section{Limitations}

Our study offers a picture of the HIV epidemic among Cambodian adolescents and the sociocultural phenomena they experience while transitioning from pediatric to adult HIV care. However, and despite our sampling methodology, the generalizability of our results to the entire population of adolescents living with HIV in Cambodia may be limited. Potential for bias due to social desirability or recall biases were minimized by validating responses against medical records whenever possible, but may not have been eliminated.

\section{Conclusions}

The considerable advancements made in reducing new infections from mother-to-child transmission indicates that a focused worldwide effort, robust political commitment and leadership at the national level can produce substantial results. The same type of concentrated focus must now be shifted to adolescents. Our study reports that social protection mechanisms are reaching a number of adolescents living with HIV in need, but others remain without support. Multi-sectoral interventions, boosting school attendance, mitigating HIV-related stigma, and expanding coverage of social protection mechanisms are necessary to improving the health and quality of life of all adolescents living with HIV in Cambodia.
Authors' contributions

SY, ST and VK conceived the study. PC and ST were responsible for data collection and data entry. SY, CN, GM and GT analyzed data interpreted the results and wrote the manuscript. All authors read and approved the final manuscript.

\section{Author details}

1 Fielding School of Public Health, University of California Los Angeles, Los Angeles, USA. ${ }^{2}$ Division of Health Research, Lancaster University, Lancaster, UK. ${ }^{3}$ KHANA Center for Population Health Research, No. 33, Street 71, Phnom Penh, Cambodia. ${ }^{4}$ National Center for HIV/AIDS, Dermatology and STD, Phnom Penh, Cambodia. ${ }^{5}$ Center for Global Health Research, Touro University California, Vallejo, USA.

\section{Acknowledgements}

The authors thank the National Center for HIV/AIDS, Dermatology and STD and KHANA's programs teams, research assistants and all participants and family for their contribution to this study. Authors thank Morten Skovdal for comments on an earlier draft. The authors'views expressed in this manuscript do not necessarily reflect the views of UNICEF Cambodia or the authors' affiliated institutions.

\section{Competing interests}

The authors declare that they have no competing interests.

\section{Availability of data and materials}

Data used for this analysis cannot be made publicly available due to ethical restriction. They are available upon request from the Principal Investigator (Dr. Siyan Yi) at siyan@doctor.com.

Consent for publication

Consent to publish was obtained from participants as stated in the informed consent form.

\section{Ethics approval and consent to participate}

The National Ethics Committee for Health Research of the Ministry of Health, Cambodia approved this study (Ref: 297NECHR). Verbal assent from adolescents and written informed consent from a parent or guardian of each participant was obtained.

\section{Funding}

Data used for this analysis were collected as part of a larger study funded by UNICEF Cambodia. 


\section{Publisher's Note}

Springer Nature remains neutral with regard to jurisdictional claims in published maps and institutional affiliations.

Received: 10 October 2017 Accepted: 21 March 2018

Published online: 28 March 2018

\section{References}

1. Patton GC, Viner RM, le Linh C, Ameratunga S, Fatusi AO, Ferguson BJ, et al. Mapping a global agenda for adolescent health. J Adolesc Health. 2010;47(5):427-32.

2. Friedman HL. Changing patterns of adolescent sexual behavior: consequences for health and development. J Adolesc Health. 1992;13(5):345-50.

3. Viner RM, Ozer EM, Denny S, Marmot M, Resnick M, Fatusi A et al. Adolescence and the social determinants of health. Lancet. 2012:379(9826):1641-52.

4. Mburu G, Hodgson I, Teltschik A, Ram M, Haamujompa C, Bajpai D, et al. Rights-based services for adolescents living with HIV: adolescent selfefficacy and implications for health systems in Zambia. Reprod Health Matters. 2013:21(41):176-85.

5. Idele P, Gillespie A, Porth T, Suzuki C, Mahy M, Kasedde S, et al. Epidemiology of HIV and AIDS among adolescents: current status, inequities, and data gaps. J Acquir Immune Defic Syndr. 2014;66(Suppl 2):S144-53.

6. Mburu G, Hodgson I, Kalibala S, Haamujompa C, Cataldo F, Lowenthal ED, et al. Adolescent HIV disclosure in Zambia: barriers, facilitators and outcomes. J Int AIDS Soc. 2014;17:18866.

7. Kim SH, Gerver SM, Fidler S, Ward H. Adherence to antiretroviral therapy in adolescents living with HIV: systematic review and meta-analysis. AIDS. 2014:28(13):1945-56.

8. Nachega JB, Hislop M, Nguyen H, Dowdy DW, Chaisson RE, Regensberg $L$, et al. Antiretroviral therapy adherence, virologic and immunologic outcomes in adolescents compared with adults in southern Africa. J Acquir Immune Defic Syndr. 2009;51(1):65-71.

9. Cruz ML, Cardoso CA, Darmont MQ, Souza E, Andrade SD, D'Al Fabbro $M M$, et al. Viral suppression and adherence among HIV-infected children and adolescents on antiretroviral therapy: results of a multicenter study. J Pediatr. 2014;90(6):563-71

10. Zanoni BC, Mayer $\mathrm{KH}$. The adolescent and young adult HIV cascade of care in the United States: exaggerated health disparities. AIDS Patient Care STDS. 2014:28(3):128-35

11. Busza J, Strode A, Dauya E, Ferrand RA. Falling through the gaps: how should HIV programmes respond to families that persistently deny treatment to children? J Int AIDS Soc. 2016;19(1):20789.

12. Fernet M, Wong K, Richard ME, Otis J, Levy JJ, Lapointe N, et al. Romantic relationships and sexual activities of the first generation of youth living with HIV since birth. AIDS Care. 2011;23(4):393-400

13. Fair $C$, Albright J. "Don't tell him you have HIV unless he's 'the one"': romantic relationships among adolescents and young adults with perinatal HIV infection. AIDS Patient Care STDS. 2012:26(12):746-54.

14. Binagwaho A, Fuller A, Kerry V, Dougherty S, Agbonyitor M, Wagner C, et al. Adolescents and the right to health: eliminating age-related barriers to HIV/AIDS services in Rwanda. AIDS Care. 2012;24(7):936-42.

15. Judd $A$, Sohn $A H$, Collins IJ. Interventions to improve treatment, retention and survival outcomes for adolescents with perinatal HIV-1 transitioning to adult care: moving on up. Curr Opin HIV AIDS. 2016;11(5):477-86.

16. Ben-Farhat J, Schramm B, Nicolay N, Wanjala S, Szumilin E, Balkan S, et al. Mortality and clinical outcomes in children treated with antiretroviral therapy in four African vertical programs during the first decade of paediatric HIV care, 2001-2010. Trop Med Int Health. 2017;22(3):340-50.

17. Bryant $M$, Beard J. Orphans and vulnerable children affected by human immunodeficiency virus in sub-Saharan Africa. Trop Med Int Health. 2017:22(3):340-50.

18. Andrews G, Skinner D, Zuma K. Epidemiology of health and vulnerability among children orphaned and made vulnerable by HIV/AIDS in subSaharan Africa. AIDS Care. 2006;18(3):269-76.

19. Brown LK, Lourie KJ, Pao M. Children and adolescents living with HIV and AIDS: a review. J Child Psychol Psychiatry. 2000;41(1):81-96.
20. Schenk KD, Michaelis A, Sapiano TN, Brown L, Weiss E. Improving the lives of vulnerable children: implications of Horizons research among orphans and other children affected by AIDS. Public Health Rep. 2010;125(2):325-36.

21. Midtbo V, Shirima V, Skovdal M, Daniel M. How disclosure and antiretroviral therapy help HIV-infected adolescents in sub-Saharan Africa cope with stigma. Afr J AIDS Res. 2012;11(3):261-71.

22. Hodgson I, Ross J, Haamujompa C, Gitau-Mburu D. Living as an adolescent with HIV in Zambia-lived experiences, sexual health and reproductive needs. AIDS Care. 2012;24(10):1204-10.

23. Menon A, Glazebrook C, Campain N, Ngoma M. Mental health and disclosure of HIV status in Zambian adolescents with HIV infection: implications for peer-support programs. J Acquir Immune Defic Syndr. 2007:46(3):349-54

24. Mburu G, Ram M, Oxenham D, Haamujompa C, lorpenda K, Ferguson L. Responding to adolescents living with HIV in Zambia: a social-ecological approach. Child Youth Serv Rev. 2014;45:9-17.

25. Cluver LD, Toska E, Orkin FM, Meinck F, Hodes R, Yakubovich AR, et al. Achieving equity in HIV-treatment outcomes: can social protection improve adolescent ART-adherence in South Africa? AIDS Care. 2016;28(Suppl 2):73-82.

26. Lowenthal ED, Bakeera-Kitaka S, Marukutira T, Chapman J, Goldrath $K$, Ferrand RA. Perinatally acquired HIV infection in adolescents from sub-Saharan Africa: a review of emerging challenges. Lancet Infect Dis. 2014;14(7):627-39.

27. Lee S, Hazra R. Achieving 90-90-90 in paediatric HIV: adolescence as the touchstone for transition success. J Int AIDS Soc. 2015:18(Suppl 6):20257.

28. Kakkar F, Van der Linden D, Valois S, Maurice F, Onnorouille M, Lapointe $\mathrm{N}$, et al. Health outcomes and the transition experience of HIV-infected adolescents after transfer to adult care in Quebec, Canada. BMC Pediatr 2016;16:109.

29. Ryscavage P, Macharia T, Patel D, Palmeiro R, Tepper V. Linkage to and retention in care following healthcare transition from pediatric to adult HIV care. AIDS Care. 2016;28(5):561-5.

30. Wiener LS, Kohrt BA, Battles HB, Pao M. The HIV experience: youth identified barriers for transitioning from pediatric to adult care. J Pediatr Psychol. 2011;36(2):141-54.

31. Bygrave H, Mtangirwa J, Ncube K, Ford N, Kranzer K, Munyaradzi D. Antiretroviral therapy outcomes among adolescents and youth in rural Zimbabwe. PLoS ONE. 2012;7(12):e52856.

32. Westling K, Naver L, Vesterbacka J, Belfrage E. Transition of HIV-infected youths from paediatric to adult care, a Swedish single-centre experience. Infect Dis. 2016;48(6):449-52.

33. Righetti A, Prinapori R, Nulvesu L, Fornoni L, Viscoli C, Di Biagio A. Transitioning HIV-infected children and adolescents into adult care: an Italian real-life experience. J Assoc Nurses AIDS Care. 2015;26(5):652-9.

34. Yi S, Ngin C, Pal K, Khol V, Tuot S, Sau S, et al. Transition into adult care: factors associated with level of preparedness among adolescents living with HIV in Cambodia. AIDS Res Ther. 2017:14:33.

35. Skinner J. Probability proportional to size (PPS) sampling. London: Wiley; 2006.

36. Sharma N, Willen E, Garcia A, Sharma TS. Attitudes toward transitioning in youth with perinatally acquired HIV and their family caregivers. J Assoc Nurses AIDS Care. 2014;25(2):168-75.

37. Bakeera-Kitaka S, Nabukeera-Barungi N, Nostlinger C, Addy K, Colebunders R. Sexual risk reduction needs of adolescents living with HIV in a clinical care setting. AIDS Care. 2008;20(4):426-33.

38. World Medical Association (WMA). Declaration of Helsinki: ethical principles for medical research involving human subjects (2008 Revision). Seoul: World Medical Association; 2008.

39. Dowshen N, D'Angelo L. Health care transition for youth living with HIV/ AIDS. Pediatrics. 2011:128(4):762-71.

40. Magnani RJ, Karim AM, Weiss LA, Bond KC, Lemba M, Morgan GT. Reproductive health risk and protective factors among youth in Lusaka, Zambia. J Adolesc Health. 2002;30(1):76-86.

41. Shackleton N, Jamal F, Viner RM, Dickson K, Patton G, Bonell C. Schoolbased interventions going beyond health education to promote adolescent health: systematic review of reviews. J Adolesc Health. 2016:58(4):382-96.

42. Seng SDT, Welle E, Mok S, Soch K, Tep S, et al. Stigma and discrimination as factors affecting the transition from paediatric to adult HIV 
care services by children living with HIV aged 12-17 in Cambodia: a qualitative exploratory study. In: International AIDS conference Abstract TUPE-286. Melbourne, Australia; 2014.

43. Mupambireyi Z, Bernays S, Bwakura-Dangarembizi M, Cowan FM. "I don't feel shy because I will be among others who are just like me...": the role of support groups for children perinatally infected with HIV in Zimbabwe. Child Youth Serv Rev. 2014;45:106-13.

44. Miles K, Edwards S, Clapson M. Transition from paediatric to adult services: experiences of HIV-positive adolescents. AIDS Care. 2004;16(3):305-14.

\section{Submit your next manuscript to BioMed Central and we will help you at every step:}

- We accept pre-submission inquiries

- Our selector tool helps you to find the most relevant journal

- We provide round the clock customer support

- Convenient online submission

- Thorough peer review

- Inclusion in PubMed and all major indexing services

- Maximum visibility for your research

Submit your manuscript at

www.biomedcentral.com/submit 